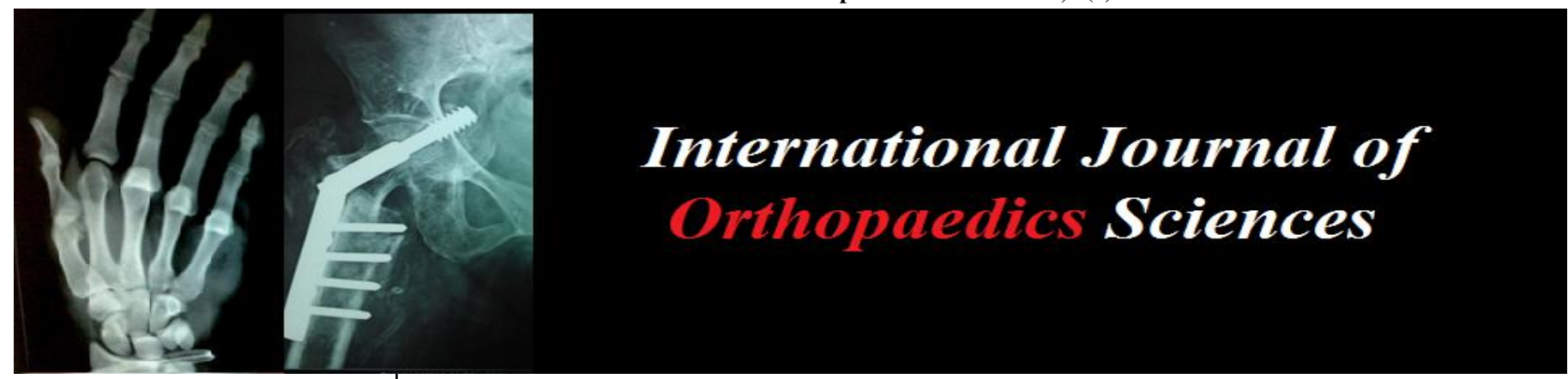

ISSN: $2395-1958$

IJOS 2017; 3(3): 151-155

(C) 2017 IJOS

www.orthopaper.com

Received: 13-05-2017

Accepted: 14-06-2017

Dr. Amaradeep G

Assistant Professor, Dept. of Orthopedics, MIMS, Mandya,

Karnataka, India

Dr. Ravikumar HS

Senior Resident, Dept.of

Orthopedics, MIMS, Mandya,

Karnataka, India

Dr. Manjappa CN

Professor, Dept.of Orthopedics, MIMS, Mandya, Karnataka, India

Dr. ShivaKumar NH

Senior Resident, Dept.of

Orthopedics, MIMS, Mandya,

Karnataka, India

Dr. Mahendra Kumar KL

Associate Professor, Dept.of Orthopedics, MIMS, Mandya,

Karnataka, India
Correspondence

Dr. Amaradeep G

Assistant Professor, Dept. of Orthopedics, MIMS, Mandya,

Karnataka, India

\section{Comparision of functional outcome in elderly patients with inter trochanteric fracture: Dynamic hip screw vs proximal femoral nail}

\author{
Dr. Amaradeep G, Dr. Ravikumar HS, Dr. Manjappa CN, Dr. Shiva \\ Kumar NH and Dr. Mahendra Kumar KL
}

DOI: $\underline{\text { http://dx.doi.org/10.22271/ortho.2017.v3.i3c.24 }}$

\begin{abstract}
Introduction: The conservative approach has high complication rate. The common problems of prolonged immobilization, decubitus ulcers, U.T.I, joint contractures, pneumonia, and thrombo-embolism contribute to the high mortality rate. The increased incidence of varus deformity and shortening results in poor function.

Methodology: This was a retrospective study carried out in department of orthopaedics, MIMS, mandya. The material for the present study was obtained from the patients visiting for follow-up in out-patient department with the diagnosis of intertrochanteric fracture femur who had undergone operative treatment between 2014 and 2015 ( 6 months elucidated after surgery at this visit)were de-identified and analysed. Results: Comparision of clinical, radiological and functional outcomes between group DHS and group PFN were presented in the Table-2 and Table-3. No patients had wound problems, union problems and screw out in both the groups. In the group DHS, 6 patient had shortening, 5 patients had restricted range of motion and collapse radiologically in 6 patients. In the group PFN, 2 patient had shortening, 2 patients had restricted range of motion and collapse radiologically in 2 patients.

Conclusion: PFN group had statistically significant improvement with respect to harris hip scoring and
\end{abstract} PCS, MCS of SF-12 health survey.

Keywords: dynamic hip screw, proximal femoral nail, inter trochanteric fracture

\section{Introduction}

Intertrochanteric fractures are defined as 'fractures involving upper end of femur through and in between both trochanters with or without extension into upper femoral shaft'. An increasing incidence of intertrochanteric fractures with advancing age is well known.

The incidence of intertrochanteric fractures varies from country to country. It has been predicted that the total no of hip fractures will reach 2.6 million by 2025 and 4.5 million by 2050. In $199026 \%$ of all hip fractures occurred in Asia whereas this figure could rise to $37 \%$ in 2025 and $45 \%$ in $2050^{[1]}$. These fractures have a long-term impact on the quality of life of patients and their carers. One-year mortality rates are high, ranging from $14 \%$ to $47 \%$ across studies ${ }^{[2]}$. The functional outcomes of patients with intertrochanteric fractures can be surprisingly poor, and many become limited to ambulation within the home and dependent on carers for the activities of daily living ${ }^{[3]}$.

The various treatment options for intertrochanteric fractures are operative and nonoperative. The non-operative method used to be treatment of choice in early 19th century when operative technique was not evolved enough to do stable fixation. Non operative treatment should only be considered in non-ambulatory or chronic dementia patients with pain that is controllable with analgesics and rest, terminal diseases with less than 6 weeks of life expectancy, unresolved medical comorbidities that preclude surgical treatment, active infectious diseases that itself a contraindication for insertion of a surgical implant and incomplete pertrochanteric fractures diagnosed by MRI. Non operative approach include reduction via traction and early mobilization within the limits of pain tolerance.

The conservative approach has high complication rate. The common problems of prolonged 
immobilization, decubitus ulcers, U.T.I, joint contractures, pneumonia, and thrombo-embolism contribute to the high mortality rate. The increased incidence of varus deformity and shortening results in poor function.

Most systems of fracture classification divide intertrochanteric fractures into stable and unstable, the most commonly used of which is the AO system. This divides intertrochanteric fractures into four types: stable trochanteric (Type A1), unstable trochanteric (Type A2), fractures at the lesser trochanter (Type A3) and subtrochanteric fractures. Optimal treatment of intertrochanteric and high subtrochanteric fractures is internal fixation via either intramedullary or extra-medullary implants, namely the proximal femoral nail (PFN) or dynamic hip screw (DHS), respectively [4-6].

The operative management of intertrochanteric fractures has evolved since usage of fixed nail plate, dynamic hip screws to which several modifications have been added to intramedullary devices. The DHS is an extra-medullary device, which consists of a lag screw inserted into the femoral head via the femoral neck, and attached to a plate on the side of the femur. The PFN is an intra-medullary device inserted from proximal to distal (cephalocondylic), through the greater trochanter, and secured via a cross pin or screw, which is passed up femoral neck into the femoral head. The PFN is biomechanically advantaged, as it lies closer to the line of weight bearing, resulting in a shorter distance between implant and hip joint, which reduces torsional strain across the implant.

The intramedullary devices offer certain distinct advantages:

1. The implant itself serves as a buttress against lateral translation of the proximal fragment.

2. The intramedullary location of the junction between the nail and lag screw makes the implant stronger at resisting the binding forces.

3. The intramedullary device has a reduced distance between the weight bearing axis and the implant that is a shorter lever arm.

4. An intramedullary device bears the bending load which is transferred to the intramedullary nail and is resisted by its contact against the medullary canal (load sharing device).

5. The intramedullary hip screw is a more biological method of fixation.

For the above mentioned reasons it was believed that the intramedullary hip screw would be superior for the fixation of intertrochanteric fractures. Whether intramedullary nailing with the PFN has any advantage over the DHS in intertrochanteric fractures remains controversial ${ }^{[7]}$. However, in many patients, and particularly in the elderly, functional recovery is more important than implant selection. The purpose of this study was to compare the functional recovery achieved with the DHS and PFN devices in elderly patients with surgically-treated intertrochanteric fractures.

\section{Materials and Method}

This was a retrospective study carried out in department of orthopaedics, MIMS, mandya. The material for the present study was obtained from the patients visiting for follow-up in out-patient department with the diagnosis of intertrochanteric fracture femur who had undergone operative treatment between 2014 and 2015 (6 months elucidated after surgery at this visit)were de-identified and analysed. The patients were randomly selected on first come and first inclusion basis. 40 patients operated operated with DHS or PFN were selected and the patients were informed about the study in all respects and informed consent was obtained from each patient. Out of 40 patients 20 patients were treated with D.H.S and 20 with P.F.N.

The inclusion criteria for the patient in this study were surgically managed intertrochanteric fracture with DHS and PFN who were more than 50 years of age and less than 80 years. The exclusion criteria were Patients treated for the compound or pathological fractures, admitted for re-operation due to various reasons and those who have not given written consent for surgery.

All the patients were carefully evaluated by detailed history to determine the cause of fracture and other diseases. The radiograph of pelvis with both hips and lateral view of the affected hip was taken. The fracture was classified using Orthopaedic Trauma Association (OTA) classification.

The important parameters assessed were:

\section{Clinical}

1. Wound condition

2. range of motion

3. Shortening

4. Harris hip score

\section{Radiological}

\section{Union}

2. Amount of collapse

3. Complication like screw cut out and $\mathrm{z}$ phenomena

To determine whether there were any differences between the two surgical procedures, comparisons were conducted on all study variables. Data were analysed using the Stata V10.0 statistical software program. Study variables were analysed and described with means, standard deviations, medians and percentages. Bivariate analysis comparing outcome variables between the two surgical procedures were conducted using $t$ tests for continuous variables with normal distributions, and Mann-Whitney tests for variables with skewed distributions. Categorical variables were compared using chi-squared test. Non-parametric regression was used to compare outcome variables between surgical procedures after adjusting for potential confounders.

\section{Results}

Out of 40 patients, 9 patients were females ( 5 in group DHS, 4 in group PFN) and 31 patients were males (15 in group DHS, 16 in group PFN). Average age of the patients in the group DHS was 54 yrs and in the group PFN was 55.5 yrs. Mode of injury, in the group DHS 11 patients had self-fall at home, 3 had injury due to assault and 6 patients had road traffic accident. In the group PFN, 10 had self-fall at home, 4 had assault and 6 patients had road traffic accident. Time of injury of most patient who had self-fall at home was early morning and late evening. Total 6 patients had fall due to slippery floor. Patients having comorbidities are mentioned in the table-1. Based on the OTA fracture classfication, type A1 present in 12 patients in group DHS and 11 patients in group PFN. Type A2 present in 8 patients in group DHS and 9 patients in group PFN. Patients ASA grading based on the comorbidities, out of 40 patients, 12 patients having grade I, 17 patients having grade II and 11 patients having grade III. Based on theOsteoporosis severity assessment by Singh's index, out of 40 patients, 22 had grade 2, 13 had grade 3, 5 had grade 4.

Comparision of clinical, radiological and functional outcomes between group DHS and group PFN were presented in the Table-2 and Table-3. No patients had wound problems, union 
problems and screw out in both the groups. In the group DHS, 6 patient had shortening, 5 patients had restricted range of motion and collapse radiologically in 6 patients. In the group PFN, 2 patient had shortening, 2 patients had restricted range of motion and collapse radiologically in 2 patients. In the group DHS and group PFN, modified HHS mean was 44.6 and 58.95.there was significant difference between two groups with higher outcome in group PFN (p-value 0.000).

The general health measure was evaluated by SF-12. Scoring for the PCS-12 and MCS-12 components of the SF-12 Health Survey proforma was performed using the SAS scoring program from the Medical Outcomes Trust. PCS-12 and MCS-12 scores range from 0 to 100 , with greater scores representing better health. Both the PCS-12 and MCS-12 scales are transformed into T-scores, normalized for the general U.S. population. The score for an individual or mean score for a group of patients is thus reported relative to a mean of 50.0 and a standard deviation of 10.0 in the general U.S. population. Consequently, the SF-12 scores for the Indian-based population used in this study are relative to the general U.S. population. The mean MCS scores of SF-12 Group DHS and Group PFN were 41.925 and 47.465 respectively. There was significant difference between two groups with p-value 0.000 in favour of group PFN. The mean PCS scores of SF-12 Group DHS and Group PFN were 42.88 and 49.565 respectively. There was significant difference between two groups with $\mathrm{p}$-value 0.000 in favour of group PFN.

\section{Discussion}

The treatment of intertrochanteric fractures has changed significantly in the last 3to 4 decades. A great variety of fixation implants has been devised and discarded. The selection of implants still merits the type of fracture and condition of patient. The development of the sliding hip screw in the 1960's saw a revolution in the management of unstable fractures. The device allowed compression of the fracture site without complications of screw cut out and implant breakage associated with a nail plate. However the extensive surgical dissection, blood loss and surgical time required for this procedure often made it a contra-indication in the elderly with co-morbidities. The implant also failed to give good results in extremely unstable and the reverse oblique fracture. In the early 90 s intramedullary devices were developed for fixation of Intertrochanteric fractures. These devices had numerous biomechanical and biological advantages over the conventional dynamic hip screw ${ }^{[8-11]}$

The optimal fixation device for trochanteric fractures is still controversial at present. Jones et al. ${ }^{[12]}$ compared the intramedullary nail (IMN), which involved gamma nail, intramedullary hip screw (IMHS), and PFN, with sliding hip screw for treatment of extracapsular proximal femoral fractures. They concluded that there was no statistically significant difference in the cut-out rate between the IMN and DHS while total failure rate and reoperation rate were greater with IMN. Parker et al. ${ }^{[13]}$ also compare gamma and other cephalocondylic intramedullary nails with extramedullary implants for extracapsular hip fractures in adults. In their systematic review the authors enrolled four studies which included PFN and Targon PF nail compared with SHS. The authors concluded that there was no significant difference between the groups in outcomes of blood loss and transfusion, fixation complications, and post-operation complications and hospital stay. In our study, DHS group had more patients affected with shortening, collapse and restricted range of motion compared to PFN group. This is probably related to mechanical properties of implants like sliding properties and sliding angle which affects collapse, shortening and range of motion. Implant DHS promotes more sliding and results in more collapse. Increased collapse in turn promotes shortening and restricted range of motion.

Regarding functional recovery, Dujardin et al. ${ }^{[14]}$ showed that hip strength and mobility progressed similarly in the first 3 months after surgery in patients treated with the DHS and in those treated with static nailing, but significant differences favouring the intramedullary nail group were apparent 6 months after surgery. This is consistent with the findings in the present study, where functional recovery was faster in PFN treated. PFN group had statistically significant improvement with respect to harris hip scoring and PCS, MCS of SF-12 health survey.

The limitation of our study is retrospective study, multiple surgeon, single follow-up 6 months after surgery.

Tables 1: Demographic parameters comparision of DHS group and PFN group.

\begin{tabular}{|c|c|c|}
\hline Parameters & Group Dhs & Group Pfn \\
\hline Age & 54 Yrs & $55.5 \mathrm{Yrs}$ \\
\hline \multicolumn{3}{|l|}{ Sex } \\
\hline Females & 5 & 4 \\
\hline Males & 15 & 16 \\
\hline \multicolumn{3}{|l|}{ Mechanism Of Injury } \\
\hline Self Fall & 11 & 10 \\
\hline Road Traffic Accident & 6 & 6 \\
\hline Assault & 3 & 4 \\
\hline Slippery Floor & 2 & 4 \\
\hline \multicolumn{3}{|l|}{ Co-Morbidities } \\
\hline Angina & 6 & 2 \\
\hline Hypertension & 8 & 2 \\
\hline Diabetes Mellitus & 6 & 2 \\
\hline Past History Of Fracture & 3 & 0 \\
\hline Visual Impairment & 5 & 2 \\
\hline Respiratory Abnormalities & 2 & 4 \\
\hline Cerebrovascular Accidents & 5 & 4 \\
\hline Associated Fracture & 3 & 0 \\
\hline Pressure Sore & 3 & 0 \\
\hline \multicolumn{3}{|l|}{ It Fractureclassification } \\
\hline A1 & 12 & 11 \\
\hline $\mathrm{A} 2$ & 8 & 9 \\
\hline \multicolumn{3}{|l|}{$\mathrm{A} 3$} \\
\hline \multicolumn{3}{|l|}{ Side } \\
\hline Left & 9 & 6 \\
\hline Right & 11 & 14 \\
\hline \multicolumn{3}{|l|}{ Asa Grading } \\
\hline I & 6 & 6 \\
\hline Ii & 11 & 6 \\
\hline Iii & 3 & 8 \\
\hline \multicolumn{3}{|l|}{ Singh's Index } \\
\hline 2 & 14 & 8 \\
\hline 3 & 3 & 10 \\
\hline 4 & 3 & 2 \\
\hline
\end{tabular}


Table 2: Clinical and radiological parameters comparision of DHS group and PFN group.

\begin{tabular}{|c|c|c|}
\hline Parameters & Dhs Group Normal/Abnormal & Pfn Group Normal/Abnormal \\
\hline Wound Condition & 20 & 20 \\
\hline Normal & 0 & 0 \\
\hline Abnormal & 14 & 18 \\
\hline Shortening & 6 & 2 \\
\hline Normal & & \\
\hline Abnormal & 15 & 18 \\
\hline Range Of Motion & 5 & 2 \\
\hline Normal & & 20 \\
\hline Abnormal & 20 & 0 \\
\hline Union & 0 & 18 \\
\hline Normal & & 2 \\
\hline Abnormal & 14 & No \\
\hline Collapse & 6 & \\
\hline Normal & No & \\
\hline Abnormal & & \\
\hline Screw Out & & \\
\hline & & \\
\hline
\end{tabular}

Table 3: Functional Outcome scores comparision of DHS group and PFN group.

\begin{tabular}{|c|c|c|c|}
\hline parameters & DHS group & PFN GROUP & P-VALUE \\
\hline Harris Hip Score & 58.95 & 44.6 & .000 \\
\hline SF-12 MCS & 41.925 & 47.465 & .000 \\
\hline SF-12 PCS & 42.88 & 49.565 & .000 \\
\hline
\end{tabular}

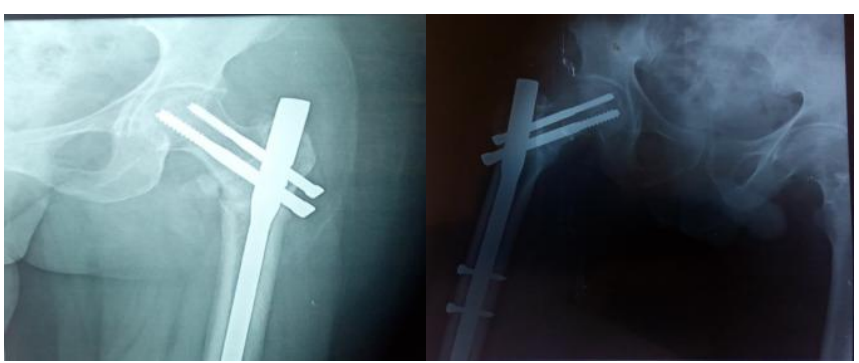

Fig 1 and 2: depicts PFN united fracture

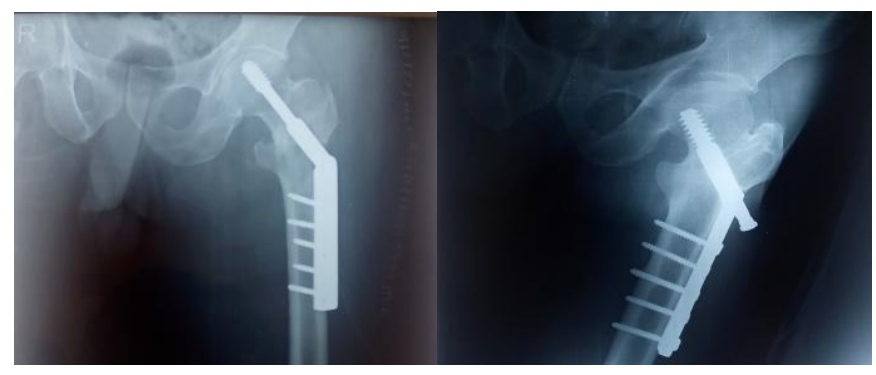

Fig 3 and 4: depicts DHS with united fracture

\section{Conclusion}

Based on the literature and our study results, PFN appears to be novel implant for inter-trochanteric fracture in elderly patients which has better functional outcome. Further, it requires better designed study to evaluate functional outcome between PFN and DHS implants in intertrochanteric fracture.

\section{Reference}

1. Melton LJ 3rd, Kearns AE, Atkinson EJ. Secular trends in hip fracture incidence and recurrence. Osteoporos Int. 2009; 20(5):687e694.

2. Holt G, Smith R, Duncan K, Hutchison JD, Gregori A. Outcome after surgery for the treatment of hip fracture in the extremely elderly. J Bone Joint Surg Am 2008; 90:1899-905.

3. Koval KJ, Heckman JD. Intertrochanteric fractures. In:
Bucholz RW, Heckman JD, editors. Rockwood and Green's Fractures in Adults. Philadelphia: Lippincott Williams \& Wilkins. 2001, 1635-63.

4. Lorich DG, Geller DS, Nielson JH. Osteoporotic pertrochanteric hip fractures: management and current controversies. Instr. Course Lect. 2004; 86:398-410.

5. Solomon L, Warwick D, Nayagam S. Apley's Concise System of Orthopaedics and Fractures, 3rd edn. London, UK: Hodder Arnold, 2005.

6. Ongkiehong BF, Leemans R. Proximal femoral nail failure in a subtrochanteric fracture: the importance of fracture to distal locking screw distance. Inj. Extra. 2007; 38:445-50

7. Fogagnolo F, Kfuri M, Jr., Paccola CA. Intramedullary fixation of pertrochanteric hip fractures with the short AO-ASIF proximal femoral nail. Arch Orthop Trauma Surg. 2004; 124:31-7.

8. Hardy D, Descamps P, Krallis P. Use of an intramedullary hip screw compared with a compression hip screw with a plate for intertrochanteric femoral fractures. A prospective randomized study of one hundred patients. J Bone Joint Surg Am. 1998; 80:618e630.

9. Harris WH. Traumatic arthritis of the hip after dislocation \& ace tabular fractures: Treated by mould arthroplasty. An end result study using a new method of result evaluation. J Bone Joint Surg Am. 1969; 51:737e755.

10. Spivak JM, Zuckerman JD, Kumme FJ. Fatigue failure of sliding hip screw in hip fractures a report of three cases. J Orthop Trauma. 1991; 3:325e331.

11. Leung KS, So WS, Shen WY, Hui PW. Gamma nails and dynamic hip screws for pertrochanteric fractures. A randomized prospective study in elderly patients. J Bone Joint Surg Br. 1992; 74:345e351.

12. Jones HW, Johnston P, Parker M. Are short femoral nails superior to the sliding hip screw? A meta-analysis of 24 studies involving 3,279 fractures," International Orthopaedics, 2006; 30(2):69-78.

13. Parker MJ, Handoll HH. Gamma and other cephalocondylic intramedullary nails versus extramedullary implants for extracapsular hip fractures in adults," Cochrane Database of Systematic Reviews, vol. 16, no. 3, Article ID CD000093, 2010. 
International Journal of Orthopaedics Sciences

14. Dujardin FH, Benez C, Polle G, Alain J, Biga N, Thomine JM. Prospective randomized comparison between a dynamic hip screw and a mini-invasive static nail in fractures of the trochanteric area: preliminary results. J Orthop Trauma. 2001; 15:401-6. 